Journal of

JALPP (PRINT) ISSN 2040-3658

Applied

JALPP (ONLINE) ISSN 2040-3666

Linguistics

Special feature

and

Professional

Practice

\title{
Communication research ethics and some paradoxes in qualitative inquiry
}

\author{
Srikant Sarangi
}

\begin{abstract}
Compliance with institutional protocols on research ethics in the practical conduct of research and its dissemination is a prerequisite in empirically grounded studies, including studies undertaken in workplace and institutional/professional settings. However, the communicative dimensions of research ethics remain largely unexplored. Drawing on seminal empirical studies in the social sciences, in this paper I delineate the communicative dimensions of research ethics in terms of ethics of access, ethics of participation, ethics of interpretation and ethics of dissemination/ intervention. In the main part of this article I elaborate each of the above dimensions in detail. I relate the ensuing discussion to the three paradoxes underpinning any qualitative inquiry: the observer's paradox, the participant's paradox and the analyst's paradox. Paradoxes, by default, are not resolvable but it remains an imperative for qualitative researchers, including those working in the domain of workplace communication, to be cognizant of the ethical nuances underpinning their research trajectories.
\end{abstract}

KeYWORDS: ETHICS OF ACCESS; ETHICS OF DISSEMINATION/INTERVENTION; ETHICS OF INTERPRETATION; ETHICS OF PARTICIPATION; OBSERVER'S/PARTICIPANT'S/ ANALYST'S PARADOX; RESEARCH ETHICS; WORKPLACE COMMUNICATION

Contact author

Srikant Sarangi, Danish Institute of Humanities and Medicine, Aalborg University, Kroghstræde 3, 9220 Aalborg Øst, Denmark.

Email: sarangi@hum.aau.dk

JALPP VOL $12.12015 @ 2019$ 94-121

https://doi.org/10.1558/jalpp.36885

(C) 2019, EQUINOX PUBLISHING 


\section{Introduction: A neglected situation in workplace communica-}

\section{tion studies}

In two seminal papers titled 'A neglected situation' (1964) and 'The interaction order' (1983), Goffman drew attention to the significance of studying interaction, not as a resource, but as a topic in its own right. In aligning with this stance, here I address the neglected situation of the ethical considerations in the study of interaction, especially in workplace communication research. Studies of workplace communication have continued to grow over the past decades - by covering not only a range of topics in sociolinguistics, pragmatics and discourse studies but also by adopting a number of methodological and analytical frameworks (Sarangi 2017). This is not the place to draw boundaries between these different terrains, but rather to give critical attention to the ethical dimension as being one of the main challenges underpinning empirical workplace communication studies. According to Sugarman (2004: 226): 'empirical work is a form of descriptive ethics, focused on describing a particular state of affairs that has some moral or ethical relevance. To extend this, empirically motivated researchers, in workplace communication studies and elsewhere, knowingly or unknowingly and to different degrees, embody the principles and practices of ethics.

Broadly speaking, workplace communication studies overlap with studies in professional and organizational communication in settings as diverse as medicine, law, social work, policing, mediation, corporate business etc. Three broad strands of workplace communication studies can be identified: (1) genre-based studies focusing on specialized written registers; (2) studies of talk and interaction in workplace settings; and (3) studies constituting a problem-centred, interventionist agenda, sometimes involving close collaboration between discourse analysts and members of various professions (Sarangi and Candlin 2011). Following Lave and Wenger (1991), professions constitute 'communities of practice', and their practice - or 'habitus', to use Bourdieu's (1977) familiar notion - emerges as a focus of attention for workplace communication scholars. According to Bourdieu, 'practice' always implies a cognitive operation, including perception as well as a socially and discursively constructed entity. In addition, 'practice' is culturally relative - both in terms of ethno-linguistic cultures and institutional/professional orders. Whatever the manifestations of 'practice', these are always historically determined and durable, while allowing for flexibility, contingency and improvisation. By extension, workplace communication researchers are bound by their shared research practices when it comes to professional ethical conduct.

In what follows, I outline the broad tenets of research ethics, interspersed with a focus specifically on the communicative dimensions. I identify four 
broad areas for particular attention: ethics of access; ethics of participation; ethics of interpretation; and ethics of dissemination/intervention. This is followed by an articulation of some of the paradoxes underpinning qualitative inquiry more generally - something that workplace communication researchers have to recognize and live with, while also trying to adopt methodological and analytical context-sensitivity.

\section{The evolution of research ethics}

There is a long history to the development of research ethics protocols, with particular reference to biomedical and clinical sciences, where participants are perceived to be vulnerable and stand to be exploited. The Nuremberg Code (1947) is the most recognized document providing guidelines for experiments on human beings, as a direct consequence of the Nazi regime's excesses and blatant violation of basic human rights and autonomous decision-making. The Declaration of Helsinki is another seminal frame of reference for the ethical conduct of research and the protection of research participants in the field of medicine, ratified by the World Medical Association (WMA) in 1964 and since amended on a number of occasions. ${ }^{1}$ The guidelines apply to clinical trials, i.e. research in which benefits of different treatments are assessed, based on principles of trial and error. A much-used version of clinical trials is 'Randomized Controlled Trials' (RCTs), where individual patients are assigned at random to receive one of the treatments under examination, with patient safety guarded at a premium. Such randomization practices in allocating participants to controlled and experimental groups have become the holy grail of laboratory-based empirical studies across the disciplines, despite such a practice being ethically consequential.

Equally pervasive in the field of biomedical research are drug trials mainly involving animal experiments, with a view to extending the research to human experiments if no adverse effects are observed. Protection of human participants is paramount here, although it is usually accepted that animal studies do not have absolute predictive value for adverse reactions in humans. Viewed from this commonly held assumption, for which there is some corroborating evidence, the very activity of scientific experiments using animals may be seen as unethical. Routine staging of public protests to highlight the issue of animal rights - at par with human rights - attests this moral tension.

More specifically, there has been reporting of unethical practices in drug trials with regard to recruitment policy, informed consent and the framing of the trial activity as 'an experiment' or 'new treatment. Therapeutic and non-therapeutic research would engage with ethical issues differently. Often, payments are made for participating in drug trials, which pertains to an unethical act. Should healthy persons be recruited to drug trials? Are they 
offered adequate information about potential side effects prior to giving informed consent?

The subject received considerable public interest in the UK in 2006, in the wake of an incident famously known as the 'Elephant man' clinical trial. Six participants became gravely ill and suffered life-changing inadvertent medical consequences. Afterwards, someone who had participated on a different trial provided an account to the media about how he suffered clinical depression that may have been triggered by a progesterone implant (Data Example 1).

\section{Data Example 1}

I'm not angry with the doctors who ran the trial - I believe they acted in good faith however, I'm surprised that no one thought to ask the volunteers about their mental health before allowing them to sign the consent form. What I know now is that hypochondriacs are 10 times more likely to suffer from depression. If I'd known that then, I wouldn't have signed. In spite of what happened to me, I haven't lost faith in the process of clinical trials. If you want new drugs, you have to accept that they need to be tested on humans. Whenever you take a drug, you can't be 100 per cent sure it won't kill you. We can't live in a risk-free society, but we need to continually strive for a better understanding of what risks are. Being human, we sometimes fall short.

[Witchalls 2006: 25]

Notions of informed consent, risk, uncertainty, altruism are alluded to in the above segment - which comprise the key aspects of biomedical research ethics. With regard to recruitment for randomized controlled trials, there is a communicative tension in researchers being optimally informative while maximizing enrolment of participants (for discursive accounts, see Roberts 2002; Barton and Eggly 2009; Ness et al. 2009; Wade et al. 2009; Barton et al. 2014a, 2014b; Shipman et al. 2014).

Another dimension to clinical trials is what is referred to as 'therapeutic misconception' (Appelbaum et al. 1982), which refers to the belief on the part of research subjects that researchers, like healthcare practitioners, are committed to safeguarding the best interests of the participants. In other words, the research participants anticipate that there would be no difference as regards how they receive care in a research project from the way it would happen in routine healthcare delivery. In reality, the researchers are more likely to follow the research protocol (constituted in double blind designs, the use of placebos, randomization of participants to treatment arms and treatments under experimentation) rather than attending to the specific needs of a patient who is now a research participant. When the healthcare practitioner is also part of the research team, there are bound to be professional ethical tensions in the performance of the complex and competing role-set (Merton 1957; Sarangi 2011 , 2016), which would be manifest at the communicative level. Healthcare 
professionals may have a conflict of interest in their duty of care to the patient while participating in a research programme. More generally, any form of action research or participatory research with elements of intervention at a contingent level does raise ethical concerns.

In order to avoid, or at least minimize, the occurrence of such adverse events, in most societies there are regulatory frameworks, known as research ethics committees. In the healthcare sector, researchers have to attend to details such as patient information sheets, gaining of informed consent and assurance of confidentiality to ensure that participation/non-participation will not affect the treatment/care plan, including participation in the research process (e.g., interviews, observations) not interfering with the clinical process. In the UK, dealing with research ethics committees amounts to the researcher's presentation of a 'respectable' and 'responsible' self (Hedgecoe 2008). The written assurances have to be orally communicated so that the actions and intentions of the researcher come across as honest and credible.

\section{The communicative dimensions of research ethics}

Researchers working with empirical study designs are mainly aware of ethical concerns at the methodological level - positioning of the researcher at the time of data gathering, dealing with issues such as informed consent, anonymization of participants to protect confidentiality, sensitivity to dissemination of findings which may have unintended consequences etc. These phases of research ethics undoubtedly involve communicative acts. Many of the ethical issues pose dilemmas - captured by metaphors such as 'walking the tight rope' or 'being torn between Scylla and Charybdis.'

I group the ethical dilemmas faced by the workplace communication researcher into four broad categories:

- Ethics of access and the observer's paradox

- Ethics of participation and the participant's paradox

- Ethics of interpretation and the analyst's paradox

- Ethics of dissemination/intervention and the paradox of rigour or relevance

In what follows I elaborate each category in detail.

\section{Ethics of access}

The starting point concerning access is the choice of research site, being invited or being accepted as a researcher and negotiating the research topic. Access also includes decisions about data-collection procedures as well as gaining informed 
consent of the participants. Each of these stages involves complex communicative acts.

In the 1970s, sociological studies of social deviance concerning marginal communities paid scant attention to the ethical aspects of access. More extreme examples include studies of heroin users (Stoddart 1974) and homosexual encounters (Humphreys 1970). Humphreys's (1970) study of the tearoom trade ('tearoom' is men's conveniences in the American homosexual slang) is concerned with accessing private homosexual encounters in public settings. He manages access to these marginalized groups by taking on the role of watchqueen to look out for the arrival of police or intruders:

A man is situated at the door or windows from which he may observe the means of access to the restroom. When someone approaches, he coughs. He nods when the coast is clear or if he recognizes an entering party as a regular. (Humphreys 1970:27)

Such a researcher stance is very different from the traditional notion of participant observation. This is more like a participation activity, as observation here slides into some form of participation in the activity, which is not unproblematic in itself as adopting a more distanced stance can disrupt the very activity one has set out to observe. However, as Humphreys points out, it is an essential commitment not only to be able to continue observing clandestine homosexual behaviour, but also to be able to draw on this experience for purposes of interpreting the specialized argot and the practices of those being observed (see the discussion of the 'participant's paradox' and the 'analyst's paradox' below).

Broadly speaking, there are two forms of data that communication researchers deal with: (1) data by observing or observational data (naturally recorded; fieldwork notes; documents/texts); and (2) asked-for or elicited data (questionnaires; research interviews). Both formats not only raise different aspects of ethics of access but also ethics of participation. Elicited data, in particular, requires different degrees of socialization involving the research site and the research participants.

Ethics of access incorporates what Labov (1972) formulated as the 'observer's paradox', also called the Hawthorne effect, which amounts to the impossibility of collecting naturally occurring data. The data we collect by declaring our research interest manifestly is deemed 'impure' or 'contaminated'. Pure and uncontaminated data can only be accessed when we are not observing or asking. Wilson (1987: 161) extends the problem as follows: 'if sociolinguists fail to produce positive arguments for the status of their data, any conclusions which are based on such data may turn out to be unfounded. The observer's paradox is more about collecting 'pure' data, with the assumption being that interpretation of such data is unproblematic. In other words, interpretive/ analytic expertise pre-exists the technology of data collection. 
Ethnography has been characterized as a non-reactive method, where the participant observer 'is interested in people as they are, not as he thinks they ought to be according to some standard of his own' (Bruyn 1966: 18). It is also a situation where the informants do not account for their behaviours and beliefs in an explicit manner, as in research interviews. This does not mean that people's everyday conduct is devoid of accountability. Bruyn identifies the following challenges in participant observation (Bruyn 1966: 19):

problems both of how to become a natural part of the life of the observed; and thereafter, how to maintain scientific integrity while affectively involved in the research. If scientific integrity is maintained, there may be problems of ethical integrity in terms of personal obligations and commitments which develop in the process of research.

According to the anthropologist Malinowski (1935: 317):

The main achievement in field-work consists, not in a passive registering of facts, but in the constructive drafting of what might be called the charters of native institutions. The observer should not function as a mere automaton; a sort of combined camera and phonographic or shorthand recorder of native statements. While making his observations the field-worker must constantly construct: he must place isolated data in relation to one another and study the manner in which they integrate. To put it paradoxically, one could say that 'facts' do not exist in sociological any more than in physical reality; that is, they do not dwell in the spatial and temporal continuum open to the untutored eye. The principles of social organisation, of legal constitution, of economics and religion have to be constructed by the observer out of a multitude of manifestations of varying significance and relevance. It is these invisible realities, only to be discovered by inductive computation, by selection and construction, which are scientifically important in the study of culture.

Selectivity is what transforms observed phenomena into reportable data, and it is the latter which are then attended to as part of the analyst's commitment. Inevitably this process of selectivity counts both as a process of decontextualization and of recontextualization. The 'tutored eye' of the observer-analyst thus assumes significance/relevance in what is constructed and reported as 'facts'.

In recent years there have been calls in many sociolinguistic and discourse analytic studies regarding integrating recorded data and ethnographic observations. However, what constitutes competent fieldwork observations and how exactly to integrate different data sources, especially when the datasets may not align with one another, remains under-addressed. In the context of genetic counselling research, Bosk (1992: xiv) formulates four commandments of fieldwork as follows:

The First Commandment: Immerse yourself in the workgroup's everyday life - its repetitive, predictable troubles, its manner of coping with them, its sense of mastery, its experiences of defeat, its shared language for understanding, its mission. 
The Second Commandment: Study the workgroup's most naturally recursive activities, especially its routines, emergencies, and mistakes; describe what workers do and say to whom, under what conditions, in these three situations.

The Third Commandment: Dramaturgically describe behaviors as solutions to universally recurrent problems of the human condition - the riddles and persistent paradoxes that inhere in a collective life.

The Fourth Commandment: Always follow this interpretive injunction when assessing self-interested claims: Humble the proud, and elevate the humble.

These commandments are not so easy to be embodied, and at a practical level different researchers may adopt different stances to such commandments. According to Bosk (1992), when the researcher is an 'invited guest' as opposed to 'an uninvited intruder', the role-relationships work differently, with differential expectations of usefulness - which will have ramifications for the researcher's methodological determination to remain detached and objective.

With regard to workplace communication studies, Hak (1999) cautions researchers not to arrive on the scene to access data with preconceived research questions. That is, workplace researchers must not pre-empt where workplace practice occurs and which aspects of workplace practice are recordable and analysable. As Hak (1999: 435) suggests:

The study should not begin with identifying and recording talk ('text') which then, subsequently, could be analysed within the 'con-text' of this specific setting, but the study should begin with getting a sense of the 'context' in which then, subsequently, 'texts' could be isolated for further analysis.

When it concerns accessing social media as discourse data, the challenges are of a different order. Communication in an internet group or via blogs makes the data publicly available, but not necessarily ethically so for research purposes (Eysenbach and Till 2001; Ess and Association of Internet Research [AoIR] 2002; Flicker et al. 2004).

Ethics of access is not just about accessing data sites as implied in the notion of the 'observer's paradox' but also concerns accessing participants' perspectives in research interview or focus group situations, as participants may not have access to such inner mechanisms. Cicourel (1974) draws attention to the problem of accessing/interpreting 'tacitly assumed meanings that are not clearly indexed. Consider also Polanyis (1958) discussion of the competent swimmer who is unlikely to know that $s /$ he keeps afloat by systematically 'refraining from emptying his lungs when breathing out and by inflating them more than usual when breathing in'. As Polanyi (1958: 49) puts it, 'the aim of a skilful performance is achieved by the observance of a set of rules which are not known as such to the person following them.' 


\section{Ethics of participation}

Here I would like to refer to two key phases of research: (1) gaining informed consent for research participation; and (2) use of participation frameworks embedded within research instruments themselves such as survey questionnaires, research interviews, focus groups, recordings of encounters etc. The researcher's role as a participant and the resulting 'participant's paradox' (Sarangi 2002, 2007) will form the focus of my discussion.

Gaining informed consent is riddled with complexities, many of which bear upon communication issues (see Shipman 2013 for a general overview on informed consent and its interactional manifestation). With regard to the written format, in terms of texture, informed consent documents in the healthcare setting may appear too legalistic - concerned with protecting the healthcare professionals rather than informing and educating the patients about potential outcomes - and thus compromising the readability and understanding of information provided (Sand et al. 2010; Sand et al. 2012). In designing and administering a consent form, one needs to bear in mind that the consent form itself is a communication instrument; it has both informational value and persuasive function. As Dennett (1991: 73-74) points out in his discussion of 'the ethics of science', people may not be used in experiments without consent; and it is impossible to gain consent without (verbal) interaction. By extension, when does a consent count as 'informed consent' if there are concerns about the processing of information prior to giving consent to participate in a research project?

In the healthcare context - whether involving recruitment of healthy individuals in drug trials or the offer of randomized controlled trials of real patients - what information is inputted into the informed consent procedure in oral or written format? How informative should 'the information sheet' be with regard to potential risks and benefits in patient outcomes? How specific should the qualitative researcher be about the scope and content of the research study, especially when the processes and outcomes of qualitative research are generally uncertain and emergent? Moreover, if the researcher wants to be explicit about the topic under study it may affect recruitment or influence what the respondents might say in an interview or in a recorded conversation. The qualitative researcher's participation in a research interview or focus group, or co-presence in a recorded event, invariably impacts what is regarded as data. In what ways can the researcher obtain 'informed consent' without being persuasive or without misleading the participants? Listing the benefits of participation, as in the case of recruitment for clinical trials, and mitigating the risks involved may amount to an act of communication underpinned by ethical consequences. 
The researcher's presence and participation in the process of observation and elicitation introduces another paradox - the 'participant's paradox' (Sarangi 2002, 2007) mentioned above. This relates to the fact that when the researcher portrays himself/herself as neutral and detached rather than as a genuine participant in the data-collection process, s/he introduces a bias in the data. Here, this concerns the activity of research participants observing the researcher as participant-observer. Goffman suggests a distinction between 'sphere of participation' and 'sphere of focused interaction' through the exemplar of the game of bridge, where a non-player (kibitzer) can participate but not interact $-\mathrm{s}$ /he can look at one or more hands and join in post-mortem discussion (Goffman 1974: 225). Broadly speaking, 'interaction' entails focused engagement, while 'participation' is co-presence in the sense of peripheral engagement. An example from the workplace communication research environment might help. The researcher present in a clinic or classroom can peripherally participate in the activity by making occasional eye contact with the ratified participants (e.g., clinicians, patients, careers, teachers, students) but not actively contribute to the discussion by answering a question directed at patients or students through voicing a personal opinion when unsolicited. Such interventions by a researcher with a third-party status comes under the rubric of 'communication ethics'.

Let us now turn to the positioning of the researcher and the artificial manufacturing of talk-data - in terms of content and interactional routines - in research interviews as a case in point. In workplace settings, the researcher may be viewed with suspicion as the invisible hand of the management, perhaps engaged in research resembling investigative journalism. Watson (1997) reports the challenge he faced when carrying out an interview-based study in an organizational setting, focusing on the middle management. Data Example 2 is from an interview relating to this (M1 and M2 are managers; TJW is the academic and the interviewer).

\section{Data Example 2}

M1: I don't think we've had a lot of professors working with us down here before.

M2: I suppose you're really just another consultant, in academic guise.

TJW: $\quad$ Absolutely not. I am not a consultant. I am here to work as part of management. I've got to earn my keep here at Parkside. I shall not be writing a report for the company at any stage, or recommending anything. I shall write a book, after I've left, using my experience here to reflect on what is happening to managerial work in modern organisations. 
M3: Oh ho. So we are going to be in a book then. That's a good laugh. All of us blokes are hairy-arsed factory managers. I don't think that you'll get a lot from us. We don't go on for your fancy management, you know, business college talk.

M2: We can easily tell you how not to do it though. We know all about fuckups. But Terry's right. I dare say we won't use the sort of language you want for your posh book.

[Watson 1997: 211-212]

Here the researcher's identity as an impartial 'professional stranger' (Agar 1980) is being challenged explicitly; the managers' strong feelings about outsiders posing as consultants are being voiced; and a line of distinction is being drawn between the posh academic researchers and the managers/workers on factory floors (lads, blokes). We can see that two different languages (discourses) marking the boundary between the researcher and the researched - are evident in terms of presentation of selves and priorities, with attendant concerns about trust and credibility. In a sense, the middle managers' threat to use their vernacular in the presence of the researcher is compatible with the search for authentic, naturalistic data, which is preferable to the informants appropriating the 'fancy management and business college talk' in an attempt to 'play' or 'play at' the research interview game, thus minimizing the so-called 'observer's paradox' (Labov 1972).

As Humphreys (1970: 169-170) reminds us: 'There are no 'good' or 'bad' methods - only 'better' or 'worse' ones. [...] Neither does any researcher ever have adequate insight for a perfect representation of his identity; it is always a matter of greater or lesser misrepresentation'

Similar situational dilemmas can be traced back to Wolfson's (1976) failed attempt to elicit responses in a spontaneous interview situation. In Data Example 3, the informant (Sub) is asked a few questions and then encouraged to develop any topic in an open format which seems to interest him/her. The intention of the interviewer (Int) was to break the interview rules and to aim at creating an informal, conversational setting to elicit narratives.

\section{Data Example 3}

[Topic: 'Life in Philadelphia', where the interviewer tells a story about a child]

Sub: Now what's the story?

Int: What's the story?

Sub: Yeah, what type of questions - are you all set up now?

Int: Well, we'll continue with what we've got. Well, I've got some more, you know.

[Wolfson 1976: 196] 
As can be seen, the informal conversational features create a problem; some informants might feel uncomfortable when they expect a formal interview format and may perhaps become suspicious about the interviewer's competence. In other words, research interview is a marked context, so interactional deviations, including stylistic shifts, are bound to be disruptive.

A more dramatic event is shown in Data Example 4, which concerns the power differential and the relational aspects of the activity type of research interview as an asymmetrical information-gathering encounter. But this asymmetry can be muted when the interviewer is of low status - and it can be counter-productive as in the example Wolfson provides where there is a role-reversal: inadvertently, the restaurant owner takes up the questioner role and the student interviewer finds herself in the interviewee role.

\section{Data Example 4}

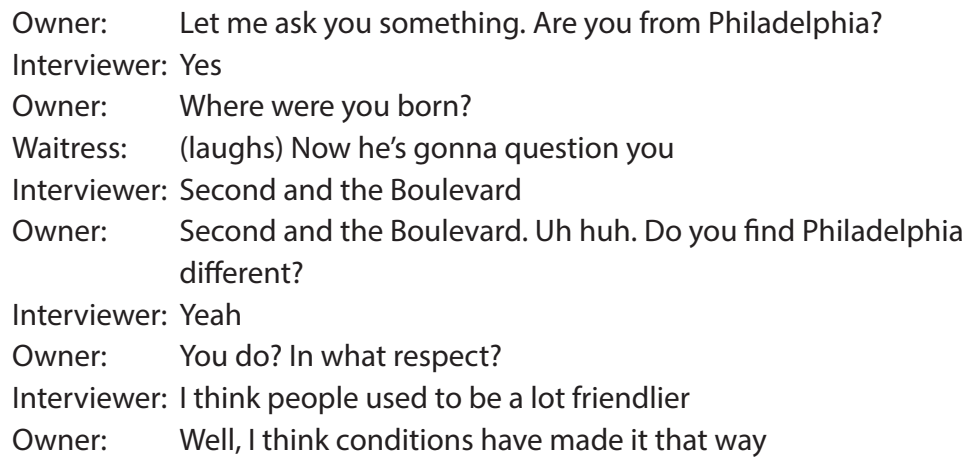

[Wolfson 1982: 68]

Further insights can be obtained from Widdicombe's (1998) study of the punk lifestyle, where the interviewees resist certain identity categories ascribed via the researcher's questioning. Consider the two short examples in Data Examples 5 and 6.

\section{Data Example 5}

01 Int: can you tell me something about your style and the way you look,

02 Int: how would you descri:be yourselves

(.7)

03 R1: huhh

(.7)

04 R1: I dunno $>$ I hate those sorts of quest [ions $<$ uhm

05 R2: [yeah horrible isn't it 


\section{Data Example 6}

01 Int: >Okay< hh how would you descri:be yourselves an your style and that (0.8)

02 MR: I could answer that in a lot of ways ((laughing voice))

03 NP: go on then

04 MR: it's disgusting. heh, heh

05 FR: urgh hh $(0.2)$

06 FR: it's colourful (0.2)

07 Int: $\mathrm{mm} \mathrm{hm}$

(2)

08 FR: I DUNNO:, I don't like describing it really it's just what you feel (0.4)

09 Int: $\mathrm{mmhm}$

[Widdicombe 1998]

Here we can see that self-presentation in interview settings is problematic, especially when the question is about self-presentation (Sarangi 2003). More generally, the researcher in his/her interviewer role, through strategic communicative styles, may influence the interviewee's responses (Rapley and Antaki 1998). This problematic scenario can be extended to include Briggs's $(1984,1986)$ concerns about the (in)compatibility of interviews as a means of acquiring information with the ways in which subjects typically convey information to one another. Briggs draws attention to the fundamental misapprehension about the nature both of the interview as a communicative event, and of the nature of the data that it produces. This has led him to convincingly argue that these oversights often blind interviewers to ensuing errors of interpretation (or to use his term, 'communicative blunders'). According to him (Briggs 1986: xiv), these blunders follow from the imposition of one set of communicative norms - those embedded in the interview situation - on a speech community that organized talk along opposing lines embodying different literacy practices (cf. Mishler 1986).

As regards a researcher's participation in research interviews, Cicourel (1964: 75) observes: 'A double responsibility is imposed on the interviewer; he must simulate spontaneous participation while evaluating the subject's views toward the interview, the observer, and their relationship.' With reference to interview as a data-gathering instrument, there appears to be an assumption that respondents, when prompted by a researcher's questions, can unproblem- 
atically access the deeper-level mental processes and relate them accurately for further scrutiny. Note how secondary data sources may fail to offer us genuine insights into participants' mental processes.

The interactional problems are also experienced in survey questionnaire interviews (Suchman and Jordan 1990) and in focus group interviews (Myers 1998, 2000). Focus groups are meant to minimize researcher bias, but they introduce more participation bias, i.e., people say what they say because it is a focus group situation. They form a group identity and accomplish (dis)agreements as part of the activity when displaying opinions (for a detailed account see Myers 1998, 2000). Both research interviews and focus groups as data settings engender participation dilemma, not only for the interviewees but also for the interviewers. Both contexts raise ethical issues about how credible the data might be.

In research interview settings, generally speaking we notice a dichotomy in the researcher's activity-specific role-set: the researcher as participant-analyst (that is, the researcher is also the interviewer) vs the researcher as discourse analyst (i.e. the researcher happens to have access to interview data). This leads to two possible alternatives in approaching interview data - interview as interaction and interview as account (Sarangi 2010). When claims are made on the basis of interview data, the content/account aspect usually takes centre stage. Grounded theory (Glaser and Strauss 1967; Strauss and Corbin 1990, 1997) and many strands of thematic analysis (e.g. Braun and Clarke 2006) pay scarce attention to the interactional aspect of the interview activity. As readers, we normally do not know the exact questions that precipitated the responses which are being analytically categorized into themes. Interviews, it must be admitted, have their own interactional lives:

But the interview is still more than tool and object of study. It is the art of sociological sociability, the game which we play for the pleasure of savoring its subtleties. It is our flirtation with life, our eternal affair, played hard and to win, but played with that detachment and amusement which give us, win or lose, the spirit to rise up and interview again and again. (Benney and Hughes 1956: 138, cited in Denzin 1970: 122)

The dichotomy between treating 'interviews' as an object of sociological inquiry as well as a research instrument is manifestly clear from the nature and purpose of the interview in a wide range of contexts. Methodologically speaking, the interview situation is often treated as a resource rather than as a topic of investigation (Silverman 1973; Miller and Glassner 1997; Sarangi 2003; see Talmy and Richards 2011 for an overview). Most researchers use 'interviews' as data-gathering instruments and subsequently interpret such interview data to reveal underlying patterns beyond the surface-level responses. 


\section{Ethics of interpretation}

Let me turn to the concept of 'ethics of interpretation'. What kind of analytic lens should we use when representing and interpreting communication data? As Mishler (1986: vii) rightly points out: 'How we make that representation and the analytic procedures we apply to it reveal our theoretical assumptions and presuppositions about relations between discourse and meaning.' The analytic situation is similar to the proverbial Occam's razor - the more assumptions we draw upon the less explanatory our interpretive framework is.

Elsewhere I have proposed the notion of the 'analyst's paradox' and its usefulness. By 'analyst's paradox' I refer to the activity of obtaining members' insights to inform analytic practice, including collaborative interpretation (Sarangi 2002, 2007) as well as contested interpretation (Sarangi 2015). The analyst's paradox should be regarded as a continuum: it is at its most extreme when interpreting different professional and organizational practices - that is, the backstage activities, e.g., case records, peer-centred talk/text in case presentations, case conferences, source texts, guidance notes etc. Professional-client encounters are easier to interpret, because we can put ourselves in clients' shoes and draw parallels to similar lived experiences - in Geertz's (1973) terms, we have access to 'experience-rich' insights. However, as already discussed earlier, there is an inherent paradox within the analyst's paradox, i.e., members' inaccessibility/inarticulation of local/native knowledge. Moreover, freezing data in order to go over it repeatedly for analytic purposes reinforces analytic bias.

The communication researcher's interpretive journey begins with the transcription and, where relevant, translation of audio- and video-recorded data. Transcription, translation and anonymization of recorded talk data should be located on the boundary between ethics of access and ethics of interpretation. As Ochs (1979) has convincingly argued, transcription/translation of data is never atheortical. Parallel to the notion of 'lost in translation' - some meaning is inevitably lost or transformed in the process of translation - we can talk about what is 'lost in transcription'. Attempts by conversation analysts to preserve the essential features of interaction in the text format are admirable, but this is not achieved without sacrificing some aspects of interaction which may have interpretive consequences (Edwards and Lampert 1993; Jenks 2011). Cook (1990) talks about transcribing infinitely, similar to the nonfinalizability of ethnography and discourse analysis (Scollon 2000). I favour a pragmatic approach to transcription, dependent on the level of analysis to be undertaken to answer the research questions posed in a recursive manner (Sarangi 2010).

In general terms, transcription is a form of representation of talk in text - which can be referred to as written talk or text talk. Drawing on Mehan's 
(1993) politics of representation, transcripts of spoken interaction are also invested with the ideology of representation of actors (Mishler 1991; Roberts 1997; Bucholtz 2000) - how authoritative and powerful actors are transcribed in standard forms, and the less powerful in nonstandard forms. At the representational level, there is also a tension between accuracy and readability. Transcription thus constitutes a socially motivated communicative act and is ideologically invested. At the communicative level, the interpretive decisions made by the transcriber have consequences. When a transcript is more of a construction or artefact in pursuit of the researcher's agenda and bias than a faithful representation of 'prior talk or interaction', the product is not only distorted, but also influences interpretation and its subsequent uptake. The activity of transcription/translation is thus subject to similar ethical considerations.

Anonymization of data to protect confidentiality is also riddled with nuances. A pragmatic approach at the level of anonymization has to attend to what research questions can be asked and pursued in light of the quality of data in hand and the mandate of confidentiality. The obligation to protect the identity of participants can at times compromise the act of interpretation. A prototypical example is the aim of analysing gesture and the need to black out the faces of participants and replace them with bidirectional arrows. Surely, we gain some insights about gaze movement by following the arrows, but this is far from the contingencies of interaction as it unfolds in real time. It is worth noting that in genetic counselling, anonymization of the genetic condition and withholding of familial relationships in the transcript will compromise interpretation of data, especially with regard to risk assessment and offer or uptake of genetic tests.

In the context of social media, we find examples of self-initiated-anonymization by participants rather than anonymization being carried out by the researcher. Such self-anonymization of actors facilitates disclosure, but ethical issues are raised about the difficulty of obtaining consent or verifying interpretations when the actors, through self-anonymization, make themselves nonauthentic and non-contactable as far as the research process is concerned.

Beyond transcription and anonymization, interpretation of data from vantage analytic standpoints is a bias introduced by the researcher. Different analytical traditions will attend to different features of communication and cast these in their preferred metalanguage. What is taken as given in one tradition becomes a topic of study in another. Motivated looking (Sarangi and Candlin 2001) - directing analytic gaze into some channels rather than others - is unavoidable even when undertaking micro-level sequential data analysis or when freezing the data for closer analysis. Findings resulting from one strand of analysis can be seen as less credible when adopting a different strand of analysis. 'Descriptive discretion', as Dunn (1978) sees it, can be epis- 
temologically alarming - how the same description of a phenomenon stands to be asserted or negated by 'two different competent, sincere and attentive observers'.

\section{Ethics of dissemination/intervention}

As we have seen so far, access to data sites, obtaining informed consent, transcribing and translating the raw data and interpreting the processed data involve acts of selection, and this challenge also extends to dissemination of findings. During the data-collection phase of a large-scale project, I recall one genetic counsellor was concerned not about consenting to clinic encounters being recorded but about how the data would be interpreted with regard to the individual's professional practice - and how findings would be disseminated beyond the unique clinic setting involving a unique case.

Generally speaking, there is no such thing as just reporting findings, as Bailey (1996: 160) argues in the context of ethnographic fieldwork:

Ideas are not insulated from social context. It is well known that we do not simply report 'the facts'. We would not be doing so even if, machinelike, we reproduced nothing but the statements of our informants, claiming to draw no conclusions. Our reporting would still be selective and would indicate where we expected truth to be found. To assert that the anthropologist's role is limited to a minimalist form of description - mere reportage of what people say, raw material without analysis - is simple-minded if not disingenuous. The choice of material is itself a form of analysis, and those who claim to respect the Other by merely reporting and refusing to analyze what the Other says are, at best, deceiving themselves.

In Bosk's (1992: xx) words: 'All ethnography becomes social history. As time passes, a description of the way things are quickly becomes an account of the way things were.' In addition, Lazarsfeld (1993) raises ethical issues in reporting qualitative findings in a quantitative language.

Dissemination of research findings concerns not only targeted peer groups via publications but also the research participants themselves. In the legal context, William O'Barr (1983: 246) points to the interface between ethics of access and ethics of dissemination/intervention:

Gaining permission to study institutions is seldom an easy matter. By their very nature, institutions are organised, established, and typically work to protect themselves from studies that reveal their inner workings. For those researchers whose experiences with institutions are just the opposite, that is, they are embraced with open arms upon approaching the institutional directors for permission to conduct research, a different issue frequently arises. This is the problem of dealing with those who see needs for radical changes and look to social science in hopeful expectation that our studies will provide the evidence and/or the means to effect changes. [...] Either way, researchers 
who approach institutions deal with formidable problems in gaining access: we must either promise to behave ourselves by not producing uncomplimentary findings, or promise to deliver what we in truth know to be difficult or nearly impossible to do.

Becker et al. (1961) capture the tension between researchers' analytic stance and their obligation to disseminate research findings. They alert us about disseminating what we might regard as 'bad' professional practice. Truth telling - if there were a consensus about truth in qualitative research - comes with risk for self and for others. As Becker et al. (1961: 15) point out:

Our purpose is not criticism, but observation and analysis. When we report what we have learned, it is important that we do so faithfully. We have a double duty - to our own profession of social observation and analysis and to those who have allowed us to observe their conduct. We do not report everything we observe, for to do so would violate confidences and otherwise do harm. On the other hand, we must take care not to bias our analyses and conclusions. Finding a proper balance between our obligations to our informants and the organisation, on the one hand, and our scientific duty, on the other, is not easy.

The above dilemmas are still topical, but these are mainly about post hoc dissemination of research findings. Equally relevant in research partnerships is the need to provide continuous feedback - 'hot feedback' - especially when the work is being taken on a collaborative footing involving participants from the workplace. Although not quite 'participatory research', tensions arise during the research process, and particularly during the act of collaborative interpretation, which calls for a reciprocity of perspectives (Sarangi 2015).

\section{Some paradoxes in qualitative inquiry}

Against the backdrop of the discussion surrounding the communicative and ethical aspects of workplace studies, I turn now to some of the paradoxes underpinning qualitative inquiry more generally. A paradox is a statement or proposition that seems self-contradictory or absurd but in reality expresses a possible truth. A fallacy, on the other hand, is a kind of error in reasoning: fallacies, as G. K. Chesterton (1874-1936) observed, 'do not cease to be fallacies because they become fashions' (Chesterton 1991 [1930]: 293). Paradoxes (similar to biases) can never be resolved, hence one has to work with them in context-sensitive ways to minimize their impact. We can talk of paradoxes and fallacies in terms of 'blind spots' in our qualitative inquiry. In many instances we have to make choices between evils, to return to the two metaphors of 'being torn between Scylla and Charybdis' and 'walking the tight rope' mentioned previously.

The best place to begin the list of paradoxes is the empiricist paradigm itself. As Chisholm (1966: 56) puts it: 
Experience, in one or another of its various senses, is said to be the source of our knowledge; every valid claim to knowledge, it is supposed, will satisfy certain empirical criteria; and these criteria, it is then concluded, may be used to determine the extent of our knowledge. Empiricism thus begins paradoxically with a general premise. [emphasis in original]

It follows, then, how the qualitative researcher positions himself/herself epistemologically and what research questions are identified for further inquiry. The circumference of asking/looking thus poses a paradox. According to Steiner (1978: xi): 'To ask larger questions is to risk getting things wrong. Not to ask them at all is to constrain the life of understanding to fragments of reciprocal irony or isolation.. This aligns with what Brumfit (2004: 397) regards as 'metaphorical pretence'. As he puts it:

[A]ll studies of social phenomena have on the one hand a concern to idealize, which is essentially a metaphorical pretence that you can isolate the phenomenon that you're looking at, and on the other hand the need to be embedded in real-world practice. Actually all phenomena are contingent because in the world things are always tied to other things. [emphasis added]

The questions we ask and the lens/gaze we adopt on the data to answer our questions are motivated, rather than being neutral and detached. As I see it, moving away from 'metaphorical pretence' in favour of 'motivational relevanices' (Sarangi and Candlin 2001) is a virtue to be desired in workplace communication studies.

We have already considered under ethics of access the notion of the observer's paradox' (Labov 1972): how the act of observation itself can contaminate the data being gathered. By extension, we only get authentic data when we are not observing or eliciting. Interview data is likely to be more contaminated than naturally occurring data. Streaming of videoed data or visual representations via 360-degree cameras do not make the captured data more authentic as far as the participants are concerned. In such circumstances the 'observer's paradox' is even further heightened, because the emic perspective is overshadowed by the technology and affordance of observation.

Let us now consider the various paradoxes involved in the act of interpreting the data. Douglas (1971: 11) formulates what he calls the 'fallacy of abstractionism, framed in terms of type-token reasoning:

Any scientific understanding of human action, at whatever level of ordering or generality, must begin with and be built upon an understanding of the everyday life of the members performing those actions. (To fail to see this and to act in accord with it is to commit what we might call the fallacy of abstractionism, that is, the fallacy of believing that you can know in a more abstract form what you do not know in the particular form.) 
In contrast, Labov and Fanshel (1977) point to the 'paradox of microanalysis': any general understanding of events, speech-language therapy included, may be distorted when specific aspects of those events become the primary focus of investigation. At the level of interpretation, Goffman (1981: 32) refers to 'the sins of noncontextuality - the assumption that bits of conversation can be analysed in their own right in some independence of what was occurring at the time and place. This echoes 'metaphorical pretence', as described by Brumfit (2004) discussed above. Consider the observation made by Martin and Bateson (1993: 9) about adopting an analytical stance:

A fine-grained analysis is only appropriate for answering some sorts of questions, and a full understanding will not necessarily emerge from describing and analysing behaviour at the most detailed level. While a microscope is an invaluable tool in some circumstances it would be useless, say, for reading a novel.

A related issue is the inability of the 'fly-on-the-wall' researcher to interpret the observed phenomenon in a manner which is aligned with the participants' perspective:

A 'fly on the wall' who did not know we were doing psychotherapy would not necessarily suspect that that was what we were doing: he would see and hear only an ordinary conversation. What defines the conversation as psychotherapy is simply our goal in conducting the conversation. (O'Hanlon and Wilk 1987: 177)

The above remark is cautionary. As researchers external to professional practice, we may lack the ability to go beyond the surface-level linguistic and interactional features associated with specialized encounters such as those of psychotherapy and other clinical settings.

The microscope as a metaphor of analytical observation/interpretation is relevant, but the selection of the lens of the microscope requires a 'tutored eye'. As Clarke (2005: 189) points out:

The analyst must steer between the Scylla of decontextualisation and the Charybdis of over-generalisation. A microscopist would remind us of the need to use a lens of appropriate magnification - neither too high power (removing essential context) nor too low power (revealing insufficient detail).

It is not just a matter of adjusting the lens of interpretation, but also the overall positioning of the communication researcher $v i s$ - $\dot{a}$-vis the profession under study. Mutual trust and respect as well as reciprocity of perspectives are integral to collaboration across boundaries. Shuy (1983: xvi-xvii) writes about conducting studies in the healthcare setting:

The point that those linguists and sociologists who work in this area wish to make to the medical profession is that we respect your technology and skills. This is no tour territory to criticize, nor do we wish to. What is our territory is social organization and 
language. If we are critical of the medical profession's use of our technology and skills it is a well-intentioned effort on our part. We ask physicians to bear with us as we attempt to unravel the complexities of doctor-patient communication. Our goal is the same as theirs: the more effective delivery of health care.

Balanced, evidence-based criticism of professional practice is possible, but this carries an element of risk and poses a dilemma. In a more general sense, this can be summarized with reference to Schön's (1983: 42) articulation of the dilemma of 'rigour or relevance':

This dilemma of 'rigor or relevance' arises more acutely in some areas of practice than in others. In the varied topography of professional practice, there is a high, hard ground where practitioners can make effective use of research-based theory and technique, and there is a swampy lowland where situations are confusing 'messes' incapable of technical solution. The difficulty is that the problems of the high ground, however great their technical interest, are often relatively unimportant to clients or to the larger society, while in the swamp are the problems of greatest human concern. Shall the practitioner stay on the high, hard ground where he [she] can practice rigorously, as he [she] understands rigor, but where he [she] is constrained to deal with problems of relatively little social importance? Or shall he [she] descend to the swamp where he [she] can engage the most important and challenging problems if he [she] is willing to forsake technical rigor?

The more we have knowledge of micro-level phenomena, the less such knowledge translates to deal with higher-order phenomena. This is true of many research endeavours in the workplace setting.

\section{Conclusion}

In this paper I have discussed two broad themes - communication research ethics and paradoxes in qualitative inquiry. Research ethics is about the physical as well as the epistemological and ontological positioning of the researcher in terms of selectivity - what to observe/record, what level of transcription, what to select for analysis and the level of interpretation, what findings to select for dissemination and to whom. The acts of 'bracketing off' and 'circumferencing in' text and context are a constant juggle. The key aspects of practical ethical conduct - what is right and what is wrong, what is good and what is bad, how means are linked to ends, how to balance harm and benefit - do extend to the communicative plane.

Workplace communication researchers need to embrace professionalism, constituted in expertise in the subject matter as well as a heightened sense of ethical awareness. Ethical dilemma - or, paradoxes, as I have formulated these - are a part of lived reality and have to be managed on a contingent basis. Many of the paradoxes alluded to above can be minimized via different 
approaches: affordable presence of the researcher; reciprocity of participants' and researchers' perspectives; joint problematization; thick participation in the data gathering process; collaborative interpretation of data; and the provision of hot feedback. Such an integrative stance can also be framed as striving towards 'ecological validity' (Cicourel 2007) - drawing upon different data sources to make the findings more credible. It therefore becomes imperative that individual researchers are 'reflexive' about their empirical practices, including interpretive claims.

\section{Notes}

1. In Humanities and Social Sciences research ethics protocols exist (see, for instance, British Sociological Association, American Anthropological Association, British Association for Applied Linguistics etc.).

2. In Greek mythology, Scylla and Charybdis are two dangers which the seavoyager Odysseus must choose between facing - a monster or a whirlpool. The term is commonly used to refer to any situation in which avoiding one danger or evil means risking another.

\section{About the author}

Srikant Sarangi is Professor in Humanities and Medicine and Director of the Danish Institute of Humanities and Medicine (DIHM) at Aalborg University, Denmark. Between 1993 and 2013 he was Professor in Language and Communication and Director of the Health Communication Research Centre at Cardiff University (UK), where he continues as Emeritus Professor. Beginning 2017, he is also Adjunct Professor at Norwegian University of Science and Technology (NTNU), Visiting Professor at University of Jyväskylä, Finland and Visiting Professor at the College of Medicine, Qatar University. In 2012, he was awarded the title of 'Fellow' by the Academy of Social Sciences, UK. His research interests are in institutional/professional discourse studies (e.g., healthcare, social work, bureaucracy, education) and applied linguistics. He is author and editor of 12 books, guest-editor of nine journal special issues and has published nearly 250 journal articles and book chapters. He is editor of Text \& Talk, Communication \& Medicine and Journal of Applied Linguistics and Professional Practice. Address for correspondence: Aalborg University, Faculty of Humanities, Kroghstræde 3, 9220 Aalborg Øst, Denmark. Email: sarangi@hum.aau.dk

\section{References}

Agar, M. (1980) The Professional Stranger: An Informal Introduction to Ethnography. New York: Academic Press.

Appelbaum, P., Roth, L. and Lidz, C. (1982) The therapeutic misconception: Informed 
consent in psychiatric research. International Journal of Law and Psychiatry 5: 319-329. https://doi.org/10.1016/0160-2527(82)90026-7

Bailey, F. G. (1996) The Civility of Indifference: On Domesticating Ethnicity. Ithaca, NY: Cornell University Press.

Barton, E. and Eggly, S. (2009) Ethical or unethical persuasion? The rhetoric of offers to participate in clinical trials. Written Communication 26 (3): 295-319. https://doi. org/10.1177/0741088309336936

Barton, E., Eggly, S., Winckles, A. and Albrecht, T. (2014a) Strategies of persuasion in offers to participate in cancer clinical trials I: Topic placement and topic framing. Communication and Medicine 11 (1): 1-14. https://doi.org/10.1558/cam.v11i1.16614

Barton, E., Eggly, S., Winckles, A. and Albrecht, T. (2014b) Strategies of persuasion in offers to participate in cancer clinical trials II: Appeals to altruism. Communication and Medicine 11 (3): 223-233. https://doi.org/10.1558/cam.v11i3.17647

Becker, H., Geer, B., Hughes, E. C. and Strauss, A. L. (1961) Boys in White: Student Culture in Medical School. Chicago: University of Chicago Press.

Benney, M. and Hughes, E. C. (1956) Of sociology and the interview: Editorial preface. American Journal of Sociology 62 (2): 137-142. https://doi.org/10.1086/221953

Bosk, C. L. (1992) All God's Mistakes: Genetic Counselling in a Paediatric Hospital. Chicago: University of Chicago Press.

Bourdieu, P. (1977) Outline of a Theory of Practice. Trans. R. Nice. Cambridge: Cambridge University of Press. https://doi.org/10.1017/CBO9780511812507

Braun, V. and Clarke, V. (2006) Using thematic analysis in psychology. Qualitative Research in Psychology 3 (2): 77-101. https://doi.org/10.1191/1478088706qp063oa

Briggs, C. L. (1984) Learning how to ask: Native metacommunicative competence and the incompetence of the fieldworkers. Language in Society 13 (1): 1-28. https://doi.org/ $10.1017 /$ S0047404500015876

Briggs, C. L. (1986) Learning How to Ask: A Sociolinguistic Appraisal of the Role of the Interview in Social Science Research. Cambridge: Cambridge University Press. https:// doi.org/10.1017/CBO9781139165990

Brumfit, C. (2004) Coping with change in applied linguistics: David Crystal and Christopher Brumfit in conversation. Journal of Applied Linguistics 1 (3): 387-398.

Bruyn, S. (1966) The Human Perspective in Sociology. Englewood Cliffs, NJ: Prentice Hall.

Bucholtz, M. (2000) The politics of transcription. Journal of Pragmatics 32: 1439-1465. https://doi.org/10.1016/S0378-2166(99)00094-6

Chesterton, G. K. (1991 [1930]) Novels on the Great War. In G. K. Chesterton (author) and L. J. Clipper (eds.) The Illustrated London News 1929-1931. Collected Works of G. K. Chesterton 35: 292-295. San Francisco: Ignatius Press.

Chisholm, R. M. (1966) Theory of Knowledge. Englewood Cliffs, NJ: Prentice-Hall. 
Cicourel, A. V. (1964) Method and Measurement in Sociology. New York: Free Press.

Cicourel, A. V. (1974) Cognitive Sociology: Language and Meaning in Social Interaction. New York: Free Press.

Cicourel, A. V. (2007) A personal, retrospective view of ecological validity. Text \& Talk 27 (5-6): 735-752. https://doi.org/10.1515/TEXT.2007.033

Clarke, A. (2005) Commentary 1: Professional theories and institutional interaction. Communication \& Medicine 2 (2): 189-191. https://doi.org/10.1515/come.2005.2.2.189

Cook, G. (1990) Transcribing infinity: Problems of context presentation. Journal of Pragmatics 14 (1): 1-24. https://doi.org/10.1016/0378-2166(90)90061-H

Dennett, D. C. (1991) Consciousness Explained. New York: Little, Brown and Company.

Denzin, N. (1970) The Research Act: A Theoretical Introduction to Sociological Methods. Hawthorne, NY: Aldine.

Douglas, J. D. (ed.) (1971) Understanding Everyday Life: Toward the Reconstruction of Sociological Knowledge. London: Routledge and Kegan Paul.

Dunn, J. (1978) Practising history and social science on 'realist' assumptions. In C. Hookway and P. Pettit (eds) Action and Interpretation: Studies in the Philosophy of the Social Sciences, 145-175. Cambridge: Cambridge University Press.

Edwards, J. A. and Lampert, M. D. (1993) Talking Data: Transcription and Coding in Discourse Research. Hillsdale, NJ: Lawrence Erlbaum Associates.

Ess, C. and Association of Internet Research (AoIR) (2002) Ethical Decision-Making and Internet Research: Recommendations from the AoIR Ethics Working Committee. Available online: http://www.aoir.org/reports/ethics.pdf

Eysenbach, G and Till, J. (2001) Ethical issues in qualitative research on internet communities. British Medical Journal 323: 1103-1105. https://doi.org/10.1136/bmj.323.7321.1103

Flicker, S., Haans, D. and Skinner, H. (2004) Ethical dilemmas in research on Internet communities. Qualitative Health Research 14 (1): 124-134. https://doi.org/10.1177/ 1049732303259842

Geertz, C. (1973) The Interpretation of Cultures. New York: Basic Books.

Glaser, B. G. and Strauss, A. L. (1967) The Discovery of Grounded Theory. Hawthorne, NY: Aldine.

Goffman, E. (1964) The neglected situation. American Anthropologist 66 (6/2): 133-136. https://doi.org/10.1525/aa.1964.66.suppl_3.02a00090

Goffman, E. (1974) Frame Analysis: An Essay on the Organisation of Experience. New York: Harper \& Row.

Goffman, E. (1981) Forms of Talk. Oxford: Blackwell.

Goffman, E. (1983) The interaction order. American Sociological Review 48 (1): 1-17. https://doi.org/10.2307/2095141 
Hak, T. (1999) 'Text' and 'con-text': Talk bias in studies of health care work. In S. Sarangi and C. Roberts (eds) Talk, Work and Institutional Order: Discourse in Medical, Mediation and Management Settings, 427-451. New York: Mouton de Gruyter.

Hedgecoe, A. M. (2008) Research ethics review and the sociological research relationship. Sociology 42 (5): 857-870. https://doi.org/10.1177/0038038508094567

Humphreys, L. (1970) Tearoom Trade: A Study of Homosexual Encounters in Public Places. London: Gerald Duckworth \& Co.

Jenks, C. (2011) Transcribing Talk and Interaction: Issues in the Representation of Communication Data. Amsterdam: Benjamins. https://doi.org/10.1075/z.165

Labov, W. (1972) Sociolinguistic Patterns. Philadelphia: Pennsylvania University Press.

Labov, W. and Fanshel, D. (1977) Therapeutic Discourse: Psychotherapy as Conversation. New York: Academic Press.

Lave, J. and Wenger, E. (1991) Situated Learning: Legitimate Peripheral Participation. Cambridge: Cambridge University Press. https://doi.org/10.1017/CBO9780511815355

Lazarsfeld, P. (1993) On Social Research and Its Language. Chicago: University of Chicago Press.

Malinowski, B. (1935) Coral Gardens and Their Magic, 2 vols. London: George Allen and Unwin.

Martin, P. and Bateson, P. (1993) Measuring Behaviour (2nd edition). Cambridge: Cambridge University Press. https://doi.org/10.1017/CBO9781139168342

Mehan, H. (1993) Beneath the skin and between the ears: A case study in the politics of representation. In S. Chaiklin and J. Lave (eds) Understanding Practice: Perspectives on Activity and Context, 241-268. Cambridge: Cambridge University Press. https://doi. org/10.1017/CBO9780511625510.010

Merton, R. K. (1957) Social Theory and Social Structure (revised edition). New York: Free Press.

Miller, J. and Glassner, B. (1997) The 'inside' and the 'outside': Finding realities in interviews. In D. Silverman (ed.) Qualitative Research, 99-112. London: Sage.

Mishler, E. G. (1986) Research Interviewing: Context and Narrative. Cambridge, MA: Harvard University Press.

Mishler, E. G. (1991) Representing discourse: The rhetoric of transcription. Journal of Narrative and Life History 1 (4): 255-280. https://doi.org/10.1075/jnlh.1.4.01rep

Myers, G. (1998) Displaying opinions: Topics and disagreement in focus groups. Language in Society 27: 85-111. https://doi.org/10.1017/S0047404500019734

Myers, G. (2000) Becoming a group: Face and sociability in moderated discussions. In S. Sarangi and M. Coulthard (eds) Discourse and Social Life, 121-137. London: Pearson.

Ness, D., Kiseling, S. and Lidz, C. (2009) Why does informed consent fail? A discourse analytic approach. Journal of the American Academy of Psychiatry \& Law 37 (3): 349-362. 
O'Barr, W. (1983) The study of language in institutional contexts. Journal of Language and Social Psychology 2 (2-4): 241-251. https://doi.org/10.1177/0261927X8300200210

O'Hanlon, B. and Wilk, J. (1987) Shifting Contexts: The Generation of Effective Psychotherapy. New York: Guilford.

Ochs, E. (1979) Transcription as theory. In E. Ochs and B. Schieffelin (eds) Developmental Pragmatics, 43-72. San Francisco: Academic Press.

Polanyi, M. (1958) Personal Knowledge: Toward a Post-Critical Philosophy. London: Routledge \& Kegan Paul.

Rapley, M. and Antaki, C. (1998) 'What do you think about...?': Generating views in an interview. Text 18 (4): 587-608. https://doi.org/10.1515/text.1.1998.18.4.587

Roberts, C. (1997) The politics of transcription. Transcribing talk: Issues of representation. TESOL Quarterly 31 (1): 67-71. https://doi.org/10.2307/3587983

Roberts, F. (2002) Qualitative differences among cancer clinical trial explanations. Social Science \& Medicine 55 (11): 1947-1955. https://doi.org/10.1016/S0277-9536(01)00323-9

Sand, K., Eik-Nes, N. L. and Loge, J. H. (2012) Readability of informed consent documents (1987-2007) for clinical trials: A linguistic analysis. Journal of Empirical Research on Human Research Ethics 7 (4): 67-78. https://doi.org/10.1525/jer.2012.7.4.67

Sand, K., Kaasa, S. and Loge, J. H. (2010) The understanding of informed consent information - Definitions and measurements in empirical studies. AJOB Primary Research 1 (2): 4-24. https://doi.org/10.1080/21507711003771405

Sarangi, S. (2002) Discourse practitioners as a community of interprofessional practice: Some insights from health communication research. In C. N. Candlin (ed.) Research and Practice in Professional Discourse, 95-135. Hong Kong: City University of Hong Kong Press.

Sarangi, S. (2003) Institutional, professional and lifeworld frames in interview talk. In H. van den Berg, M. Wetherell and H. Houtkoop (eds.) Analysing Race Talk: Multidisciplinary Approaches to the Interview, 64-84. Cambridge: Cambridge University Press.

Sarangi, S. (2007) The anatomy of interpretation: Coming to terms with the analyst's paradox in professional discourse studies. Text \& Talk 27 (5-6): 567-584. https://doi. org/10.1515/TEXT.2007.025

Sarangi, S. (2010) Practising discourse analysis in healthcare settings. In I. Bourgeault, R. DeVries and R. Dingwall (eds) The SAGE Handbook of Qualitative Methods in Health Research, 397-416. London: Sage. https://doi.org/10.4135/9781446268247.n21

Sarangi, S. (2011) Role hybridity in professional practice. In S. Sarangi, V. Polese and G. Caliendo (eds) Genre(s) on the Move: Hybridisation and Discourse Change in Specialised Communication, 271-296. Naples: Edizioni Scientifiche Italiane (ESI).

Sarangi, S. (2015) Experts on experts: Sustaining communities of interest in professional discourse studies. In M. Gotti, S. Maci and M. Sala (eds) Insights into Medical Communication, 25-47. Bern: Peter Lang. 
Sarangi, S. (2016) Activity types, discourse types and role types: Interactional hybridity in professional-client encounters. In D. R. Miller and P. Bayley (eds) Hybridity in Systemic Functional Linguistics: Grammar, Text and Discursive Context, 154-177. Sheffield: Equinox.

Sarangi, S. (2017) Editorial: Engaze'ment with text and talk. Text \& Talk 37 (1): 1-23. https://doi.org/10.1515/text-2017-1000

Sarangi, S. and Candlin, C. N. (2001) Motivational relevancies: some methodological reflections on social theoretical and sociolinguistic practice. In N. Coupland, S. Sarangi and C. N. Candlin (eds) Sociolinguistics and Social Theory, 350-388. London: Pearson.

Sarangi, S. and Candlin, C. N. (2011) Professional and organisational practice: A discourse/ communication perspective. In C. N. Candlin and S. Sarangi (eds) Handbook of Communication in Organisations and Professions, 3-58. Berlin: De Gruyter Mouton.

Scollon, R. (2000) Methodological interdiscursivity: An ethnographic understanding of unfinalisability. In S. Sarangi and M. Coulthard (eds) Discourse and Social Life, 138-154. Harlow: Pearson.

Schön, D. (1983) The Reflective Practitioner: How Professionals Think in Action. New York: Basic Books.

Shipman, H. E. (2013) Consent-in-interaction. In eLS: Citable Reviews in the Life Sciences. https://doi.org/10.1002/9780470015902.a0025146

Shipman, H., Clarke, A. and Sarangi, S. (2014) Accounts of consent: Orienting to self-other relations regarding motivation to participate in cancer bio-banking. Communication \& Medicine 11 (1): 69-84. https://doi.org/10.1558/cam.v11i1.17324

Shuy, R. (1983) Sociolinguist's foreword. In S. Fisher and A. D. Todd (eds) The Social Organization of Doctor-Patient Communication. Norwood, NJ: Ablex.

Silverman, D. (1973) Interview talk: Bringing off a research instrument. Sociology 7 (1): 32-48. https://doi.org/10.1177/003803857300700103

Steiner, G. (1978) On Difficulty and Other Essays. Oxford: Oxford University Press.

Stoddart, K. (1974) Pinched: Notes on the ethnographer's location of argot. In R. Turner (ed.) Ethnomethodology, 173-179. Harmondsworth: Penguin.

Strauss, A. L. and Corbin, J. M. (1990) Basics of Qualitative Research: Grounded Theory Procedures and Techniques. Newbury Park, CA: Sage.

Strauss, A. L. and Corbin, J. M. (1997) Grounded Theory in Practice. Thousand Oaks, CA: Sage.

Suchman, L. and Jordan, B. (1990) Interactional troubles in face-to-face survey interviews. Journal of the American Statistical Association 85 (409): 232-241. Reprinted in M. Lynch and W. Sharrock eds. (2003) Harold Garfinkel, Volume 2, 381-400. London: Sage.

Sugarman, J. (2004) The future of empirical research in bioethics. Journal of Law, Medicine and Ethics 32 (2): 226-231. https://doi.org/10.1111/j.1748-720X.2004.tb00469.x 
Talmy, S. and Richards, K. (eds) (2011) Qualitative Interviews in Applied Linguistics: Discursive Perspectives. Special issue of Applied Linguistics 32 (1).

Wade, J., Donovan, J. L., Lane, J. A., Neal, D. E. and Hamdy, F. C. (2009) It's not just what you say, it's also how you say it: Opening the 'black box' of informed consent appointments in randomised controlled trials. Social Science \& Medicine 68: 2018-2028. https://doi. org/10.1016/j.socscimed.2009.02.023

Watson, T. J. (1997) Languages within languages: A social constructionist perspective on multiple managerial discourses. In F. Bergiela-Chiappini and S. Harris (eds) The Languages of Business: An International Perspective, 211-227. Edinburgh: Edinburgh University Press.

Widdicombe, S. (1998) 'But you don't class yourself': The interactional management of category membership and non-membership. In C. Antaki and S. Widdicombe (eds) Identities in Talk, 52-70. London: Sage.

Wilson, J. (1987) The sociolinguistic paradox: Data as a methodological product. Language \& Communication 7 (2): 161-177. https://doi.org/10.1016/0271-5309(87)90006-1

Witchells, C. (2006) One man's experience of a clinical trial. The Observer, 19 March. Available online: https://www.theguardian.com/society/2006/mar/19/health.medicineandhealth

Wolfson, N. (1976) Speech events and natural speech: Some implications for sociolinguistic methodology. Language in Society 5: 189-209. https://doi.org/10.1017/ S0047404500007028

Wolfson, N. (1982) CHP: The Conversational Historical Present in American English Narrative. Dordrecht: Foris Publications. https://doi.org/10.1515/9783110851694 